\title{
Augusto y las colonias de la Hispania meridional
}

\author{
Cristóbal GonzÁLEZ RoMÁN \\ Universidad de Granada \\ cgroman@ugr.es
}

\section{RESUMEN}

La fundación de colonias por Augusto se llevo a cabo tanto en Italia como en las provincias. El número de colonias romanas conocidas en el sur de Hispania es excepcional. En el presente trabajo procedemos a realizar un estado de la cuestión sobre aspectos fundamentales de las mismas tales como su adscripción fundacional y la composición de sus colonos.

Palabras clave: Augusto. Ciudades. Colonias. Hispania.

\section{Augustus and the Colonies of Southern Hispania}

\begin{abstract}
Augustus' colonial foundations took place both in Italy and the provinces. The number of known Roman colonies in southern Spain is outstanding. In the current work, we review the main aspects of these colonies such as their foundational adscription and the settlers who compose them.
\end{abstract}

Key Words: Augustus. Cities. Colonies. Hispania.

Entre los hitos fundamentales del Principado de Augusto se encuentra su actividad colonial. La importancia de su valoración histórica puede apreciarse en la relevancia cuantitativa del número de fundaciones que le han sido atribuidas en el territorio itálico y en el marco imperial; la trascendencia de sus consecuencias en el orden cualitativo es incuestionable, ya que propició una remodelación sustancial de la relaciones Italia-provincias a través de la proyección de la civitas al territorio conquistado. Ambos fenómenos justifican la atención prioritaria de la investigación sobre esta cuestión, que se inicia en los albores de los estudios sobre la Historia de Roma en el s. XIX y llega de forma continuada hasta nuestros días. ${ }^{1}$

1 Cf. Mommsen 1883, 161-213; Kornemann cols. 510-588; Pais 1923; Grant 1946, 205-289 y 302-308; VitTinghoff 1951, 96-139; García y Bellido 1959, 475-503; Brunt 1962; SAlmon 1969, 128-164; BrunT 1971, 259-265, 589-601 y 608-610; GabBa 1973, 459-471; Lassère 1977, 201-233; KePPIE 1983, 41-87; Mann-Roxan 1983; Craco Ruggini 1987; JacQues - Scheid 1990, 238-245; CraWford 1996; LafFi 2003, 51-52; CAPogrossi Colognesi - GabBa ed. (2006). 
No obstante y de forma paradójica, la tradición literaria clásica apenas si reseña su desarrollo; Veleyo Patérculo, ${ }^{2}$ en un pasaje corrupto alude a rebeliones de soldados, a las que Octaviano en los momentos previos a Accio puso fin mediante la combinación de severidad y medidas de gracia y a través del envío de asentamientos de soldados a las tierras públicas de la "colonia campana" y posiblemente a Creta, aunque vuelvo a insistir que el texto es confuso. Tácito omitió cualquier referencia a la política colonial. ${ }^{3}$ Suetonio apenas si la menciona y tan sólo nos recuerda que incrementó la población de Italia con la fundación de 28 colonias creadas bajo sus auspicios. ${ }^{4} \mathrm{En}$ el s. III, Dión Casio se refirió a la misma de pasada en una brevísima referencia, ${ }^{5}$ que se enmarcaba en el contexto de la actividad desarrollada en el occidente romano por Augusto en los años 15 y 14 a.C. con anterioridad a su regreso a la ciudad de Roma; en la mismas se nos informa que en estos años colonizó numerosas ciudades en la Galia y en Hispania.

La información sobre el fenómeno concomitante de la extensión de la ciudadanía romana en época de Augusto tampoco suscitó una atención prioritaria en la tradición literaria clásica, pese a su trascendencia. Suetonio reseñó su actitud restrictiva en la concesión de los derechos ciudadanos y mencionó, como ejemplos, la denegación de las peticiones puntuales realizadas por Tiberio e incluso por Livia. La explicación dada por Suetonio a la actitud del príncipe se centra fundamentalmente en su oposición a la vulgarización de la ciudadanía a través de su difusión e, incluso, en la sanguinis incorruptum servare populum ${ }^{6}$ considero que ambas explicaciones, es decir la restricción del privilegio y la identidad étnica, se adaptaban más al desideratum secular de la nobilitas que a la difusión de la civitas durante la República tardía y el Principado.

Las referencias de Dión Casio son también escuetas en relación con la extensión de la ciudadanía y no incluyen valoraciones sobre la actitud del príncipe en esta cuestión; tan sólo se limitan a reseñar que después de haber concluido toda su actividad en las provincias de Germania, Galia e Hispania retornó a Roma; de forma explícita, pero breve, reseña como asuntos que le ocuparon durante su estancia en estos territorios del occidente del Imperio la recaudación y la distribución de dinero, así como la concesión de la libertad y de la politeia a algunos y la exclusión de otros. ${ }^{7}$ Considero que deben subrayarse semejantes precisiones, debido a que estos tres ámbitos -régimen impositivo, libertas y civitas - constituyen los tres elementos fundamentales de las relaciones entre el privilegio y la dependencia, entre Roma e Italia como centros del Imperio y el mundo dependiente, pero en ebullición cada vez más intensa, de las provincias.

La contraposición de tan escuetas informaciones es enorme en comparación con la atención que se presta al fenómeno de la colonización romana en las Res Gestae

2 Vell. Pat., II 81.

3 Cf. Segura Ramos 2004, 277-283.

4 Suet., Aug. 46. Cf. Syme 1939 (trad. 1989), 459-461; Millar 1984, 50-51.

5 Cass. Dio, LIV 7.

6 Suet., Aug. 40.3. Cf. Millar 1977, 479-480.

7 Cass. Dio, LIV 25. 
Divi Augusti; de hecho, existen referencias en cinco de sus capítulos a la actividad llevada a cabo por el príncipe en relación con las colonias y los colonos romanos. Indudablemente, la visión del príncipe, expresada en este documento, está llena de contenidos encomiásticos y propagandísticos; R. Syme lo consideraba como la "cima de la literatura de apología"; ${ }^{8}$ no obstante, el contraste con el relativo silencio o, al menos, con la minusvaloración de la tradición literaria posterior debemos explicarlo también en términos contextuales y, específicamente, en relación con la relevancia del programa de fundaciones coloniales como elemento fundamental de la resolución de la revolución romana. El interés decayó posteriormente y la atención se centró en otros aspectos, que obedecían al interés de sus autores y al carácter del público de sus obras.

Las Res Gestae Divi Augusti subrayan en diversos capítulos tanto la relevancia cuantitativa de las colonias fundadas por el princeps como la importancia del número de colonos asentados en territorio itálico y provincial. Concretamente, la preeminencia que Augusto adscribía al fenómeno se aprecia en su presencia en el inicio del documento y más concretamente en el capítulo III, 3 de las Res Gestae; en el mismo se especifica, en el contexto de las victorias obtenidas en las guerras civiles y contra los pueblos extranjeros, el juramento de fidelidad recibido de quinientos mil ciudadanos, de los que deduxi in colonias aut remisi in municipia sua stipendis emeritis millia aliquanto plura quam trecenta et iis omnibus agros adsignavi aut pecuniam pro praemis militiae dedi. ${ }^{9}$

Semejante referencia tiene una connotación sociológica evidente; el sacramentum nos remite sin duda alguna a la relación específica entre el príncipe y los milites, y, en consecuencia, nos proporciona una clara definición del contexto militar en el que se desarrolló tan extenso juramento de fidelidad a Augusto; la especificación posterior subraya este carácter y cuantifica su composición al enumerar explícitamente un conjunto de algo más de trescientos mil milites, que se integraron parcialmente tras su licenciamiento en las deductiones de colonias o regresaron a sus municipios de origen; todos ellos se vieron beneficiados por la asignatio de tierras y por compensaciones en metálico como premio por su apoyo militar.

La valoración del conjunto de soldados compensados con distribuciones de tierra recogía la actividad desarrollada por Augusto durante su Principado. Obviamente, la distribución pormenorizada se encuentra condicionada por la documentación, que tan sólo nos ofrece algunos indicios sobre su secuencia; precisamente, éstos últimos han permitido a P. A. Brunt proponer una distribución del conjunto de los legionarios beneficiados por la asignatio; ${ }^{10}$ en ella destacan los años posteriores a la victoria de Actium, es decir, el periodo 30-28 a.C. con 85.000 veteranos, y el 14 a.C. con 70.000; el conjunto se completa con 40.000 con anterioridad al 31 a.C., 50.000 en los años 27-15 a.C. y 30.000 para el periodo comprendido entre el 7 y el 2 a.C.

8 Syme 1939 (trad. 1989), 606. Sobre ediciones de las Res Gestae, remito al texto latino de BRUNT MOORE, 1967 y al texto griego de EHRENBERG - JONES, 1955; sobre ediciones, traducciones y comentarios posteriores, cf. Alvar EzQuerra, 1980-1981; Scheid 2007; CoOley 2009.

9 Cf. Brunt 1971, 339-342; Keppie 1983, 86.

10 Brunt 1971, 341. Cf. asimismo KePpIE 1983, 86. 
Uno de los elementos que nos permiten aproximarnos a una mayor precisión cronológica está constituido por las referencias de las Res Gestae a la adquisición de tierras. A ella se refiere el capítulo 16, en el que Augusto se ufana de haber introducido una innovación excepcional en las prácticas tradicionales romanas relativas a la fundación de ciudades en tierras públicas, anexionadas o adquiridas por el Senado y el Pueblo romano; concretamente, se trataba de la compra de tierras con fondos propios, con las que procedió a la asignatio de parcelas a sus soldados licenciados. En el texto se incluye una pormenorización explícita de la puesta en práctica de este procedimiento con la mención de su desarrollo durante diversos consulados. ${ }^{11}$ La primera de las adquisiciones de tierras mencionadas correspondió al consulado de M. Licinius Crasus y Gn. Cornelius Lentulus Augur, es decir, en el 14 a.C.; en consecuencia, estamos en el contexto de las reformas introducidas por Augusto en las provincias occidentales, que se reseña en el mencionado pasaje de Dión Casio. En una segunda referencia dentro del mismo capítulo, Augusto alude a la continuidad de esta práctica con posterioridad y menciona explícitamente que la llevó a cabo durante los años del consulado de Ti. Claudius Nero y Gn. Calpurnius Piso, y de C. Antistius Vetus y D. Laelius Balbus, que corresponden respectivamente a los años 7 y 6 a.C.; y posteriormente en los de C. Calvisius Sabinus y L. Pasienus Rufus, de L. Cornelius Lentulus y M. Valerius Mesala, y de L. Gallius Caninio y $Q$. Fabricius, que transcurrieron en los años 4,3 y 2 a.C.

En principio, podría pensarse que la compra de tierras y la ulterior asignación tan solo habría afectado a los municipios, a los que el texto de las Res Gestae se refiere con la expresión militibus solvi municipis; sin embargo, el mismo Augusto subrayó que practicó esta misma política de forma indistinta en los agri municipales y coloniales. Tampoco fue una práctica privativa del privilegiado suelo itálico; de hecho, la compra de tierras para la adsignatio se realizó de forma indistinta en Italia y en las provincias; la única particularidad que se anota en el texto en relación con ambos territorios es la del contraste de las sumas invertidas, que en Italia alcanzaron los 600 millones, mientras que en las provincias se redujo a menos de la mitad, concretamente a 260 millones de sestercios.

Los favores del príncipe en relación con los ciudadanos de las colonias no se limitaron al hecho fundacional originario y a la correspondiente asignación de tierras; el vínculo entre el imperator y sus milites, convertidos en colonos, se fomentó durante todo el Principado a través de diversos procedimientos de los que las Res Gestae mencionan explícitamente la distribución de congiaria. Concretamente, en el capítulo 15 se menciona, entre las actividades llevadas a cabo durante su duodécimo consulado, correspondiente al 5 a.C., la distribución de un congiario de sesenta denarios a trescientos veinte mil ciudadanos de la plebe urbana de Roma; la donación favoreció también a los colonos, de los que se explicita que eran soldados de Augusto; se les dio mil sestercios a cada uno con fondos procedentes de los botines de la guerra; el número de los beneficiados por este congiario triunfal se estipula en cerca de ciento veinte mil hombres en las colonias. La valoración de los afectados resulta de interés

11 Degrassi 1952, 4-5. 
en tanto que puede relacionarse con las cifras mencionadas en el capítulo 3 de las Res Gestae, en el que se cuantifica en trescientos mil el conjunto de los emeriti que integraron las deductiones de colonias o que retornaron a sus municipios de origen. Si se acepta esta relación entre ambas referencias, podemos pensar que los colonos beneficiados por el congiario pudieron corresponder, a pesar de que no se explicite, tanto a Italia como a las provincias.

La relevancia de las fundaciones coloniales en la visión de Augusto de su obra le lleva también a una recapitulación final en el capítulo 28 , dedicado exclusivamente a su inventario; a pesar de que este texto es sobradamente conocido, creo necesario recordar literalmente su contenido: "Fundé colonias de soldados en África, Sicilia, Macedonia, las dos Hispanias, Acaya, Asia, Siria, Galia Narbonense y Pisidia. Italia, sin embargo, tiene 28 colonias fundadas bajo mi autoridad, que durante mi vida fueron celebérrimas y muy populosas".

Me llama la atención en esta referencia la alusión a las dos Hispanias por el hecho de que la expresión contrasta con la configuración definitiva del territorio peninsular durante el Principado en tres provincias. Aún a riego de especular y de ser peligrosamente ocurrente, me atrevo a sugerir una doble explicación no excluyente de carácter geográfico e histórico; la primera implicaría ciertamente una mera justificación de la expresión por la ubicación cercana o lejana de los territorios; creo preferible, no obstante, la interpretación histórica, que debemos relacionar con la propia secuencia de la redacción del documento y con el contexto cronológico explícito de las deductiones; éstos pudieron realizarse con anterioridad a la segregación en dos provincias del territorio correspondiente a la provincia hispana más lejana, es decir, la Hispania Ulterior, en la que se incluían originariamente los distritos mineros del Alto Guadalquivir y altiplanos granadinos, segregados ulteriormente a favor de la Citerior.

Al margen de estas consideraciones, las referencias de las Res Gestae marcan un doble contexto que debemos tener en cuenta para la reconstrucción y explicación histórica de la colonización augustea. El primero es de carácter sociológico y restringe fundamentalmente la procedencia de los colonos partícipes en las deductiones al ámbito estrictamente militar; en consecuencia, las colonias fundadas por Augusto estuvieron integradas mayoritariamente por emeriti; este hecho se pone especialmente de manifiesto en la clara distinción que se realiza en el capítulo tercero de las Res Gestae entre los milites emeriti que fueron remitidos a sus municipios de origen y aquellos que pasaron a ser colonos y se integraron en las correspondientes deductiones; en consecuencia, se trataba de individuos que se encontraba integrados ya en la civitas y poseían los derechos de ciudadanía.

El segundo elemento a destacar es de orden cronológico; las Res Gestae fija como el momento fundamental de las fundaciones coloniales por Augusto los años inmediatos a su victoria definitiva en la guerra civil en Accio; los recursos necesarios fueron proporcionados por el príncipe y procedían de los ingentes beneficios de sus victorias en las guerras civiles y en sus conquistas; subrayo el hecho de que se procedió con ellos a la compra de tierras en suelo provincial por la no despreciable cantidad de 260 millones de sestercios. Esta práctica tendría continuidad con posterioridad a lo largo de su Principado, como se pone de manifiesto en el importante conjunto 
de consulados, referidos en el capítulo 16 de las Res Gestae, en los que se reiteró la adquisición de tierras coloniales con fondos privados del príncipe.

Entiendo que este excurso constituye un contexto apropiado para aproximarnos a la reconstrucción de la proyección específica de las fundaciones coloniales de Augusto en la Hispania meridional. Utilizo una delimitación geográfica en lugar de la pertinente administración provincial romana porque me permite incluir en el presente trabajo los territorios mineros del Alto Guadalquivir y de los altiplanos de la actual provincia de Granada; éstos formaban parte originariamente, en el 27 a.C., de la provincia senatorial de la Bética y tan sólo con posterioridad, en los años 16-13 a.C. o entre el 13 y el 7 a.C., pasaron a formar parte de la provincia imperial Citerior Tarraconense.

El conjunto de las colonias romanas documentadas en este territorio en el actual estado de la documentación lo sistematizamos en el siguiente cuadro:

\begin{tabular}{|c|c|c|c|c|}
\hline Título colonial & Ubicación & Tribus & Origen colonos & Privilegios \\
\hline Iulia Gemella Acci & Guadix (Gr.) & Pupinia y Galeria & Leg. I y II & Ius Italicum \\
\hline Asido Caesarina & Medina Sidonia (Ca.) & Desconocida & Desconocido & \\
\hline $\begin{array}{l}\text { Augusta Firma } \\
\text { Astigi }\end{array}$ & Écija (Se.) & Papiria & $\begin{array}{l}\text { Leg. II Pansiana, IIIII } \\
\text { Macedónica y VI } \\
\text { Victrix }\end{array}$ & Immunitas (?) \\
\hline Corduba Patricia & Córdoba & Sergia y Galeria & Leg. Desconocida & \\
\hline Hasta Regia & Mesa de Asta (Jerez, Ca.) & Sergia & Desconocido & \\
\hline Romula Hispalis & Sevilla & Sergia y Galeria & $?$ & \\
\hline $\begin{array}{l}\text { Iliturgi Forum } \\
\text { Iulium }\end{array}$ & Mengíbar (Jaén) & Galeria & Desconocido & \\
\hline Ituci Virtus Iulia & $\begin{array}{l}\text { Torreparedones-Baena } \\
\text { (Cor.) }\end{array}$ & Galeria & Desconocido & Immunitas \\
\hline Salaria & Úbeda (Jaén) & \begin{tabular}{|l|} 
Sergia \\
\end{tabular} & Desconocido & \\
\hline $\begin{array}{l}\text { Iulia Traducta } \\
\text { Tingentera }\end{array}$ & Algeciras (Ca.) i & Desconocida & $\begin{array}{l}\text { Gentes de Zilis, } \\
\text { Tingisy y col. } \\
\text { Romanos }\end{array}$ & \\
\hline $\begin{array}{l}\text { Augusta Gemella } \\
\text { Tucci }\end{array}$ & Martos (Jaén) & $\begin{array}{l}\text { Sergia, Galeria y } \\
\text { Voltinia } \\
\end{array}$ & $\begin{array}{l}\text { Leg. IIII Macedonica, } \\
\text { X Gemina }\end{array}$ & Immunitas \\
\hline Ucubi Virtus Iulia & Espejo (Cor.) & Galeria & Desconocido & Immunitas \\
\hline Genetiva Urso & Osuna (Sev.) & Sergia y Galeria & Leg. XXX & Immunitas \\
\hline
\end{tabular}

Los datos presentes en el cuadro deben estimarse como provisionales y condicionados por el estado de la documentación, especialmente de la epigráfica, que puede introducir modificaciones en el futuro. En este sentido, cito como ejemplo el caso de Iliturgi Forum Iulium, ubicado en una posición estratégica en el Alto Guadalquivir; la ciudad es mencionada por Plinio en la Naturalis Historia (3.3.10) con esta denominación y como tal se acepta su estatuto municipal. Su promoción al rango de colonia debe aceptarse actualmente y se fundamenta en un epígrafe honorífico dedicado a Adriano por la Res Publica Coloniae Fori Iuli Iliturgitani con la correspondiente 
autorización decurional; el epígrafe, actualmente desaparecido, fue transmitido por F. Rus Puerta y considerado falso por E. Hübner; la actualización del CIL ha permitido la revisión de la interpretación aceptada hasta nuestros días. ${ }^{12}$

El listado propuesto incluye trece colonias, cifra que supera las nueve colonias de la Bética, usualmente citadas, siguiendo el inventario de Plinio; subrayo que la información de la Naturalis Historia remitía como marco de su información a la obra geográfica de Augusto y al Orbis Pictus de M. Agripa, ${ }^{13}$ que podemos datar entre el 7 y el 2 a.C. La explicación del aumento del número de colonias se encuentra ante todo en la inclusión de Acci y Salaria, que fueron segregadas de la Bética en las mencionadas remodelaciones territoriales, posteriores a su momento fundacional; Augusto pretendía con el trasvase de estas zonas a la Citerior Tarraconense el control de los estratégicos yacimientos de hierro, plata, sal, etc., existentes en el entorno de las colonias. Se incluyen también Iulia Traducta, cuyo rango colonial es mencionado por Estrabón (3.1.8), y la aludida Iliturgi en atención al rehabilitado epígrafe.

En relación con la actividad colonial de Augusto en la Hispania meridional, debemos ante todo intentar de nuevo una aproximación, ciertamente provisional, al debatido problema del momento fundacional de estas colonias. Como es bien conocido, la cuestión fundamental se centra en las posibilidades de adscripción de la deductio de estas colonias a César o a su hijo adoptivo. El debate historiográfico ha sido enorme y se incardina en el marco general de las fundaciones coloniales que se realizaron tras la muerte de César, en la etapa triunviral, en el periodo de la auctoritas excepcional de Octaviano, posterior a Accio, y durante el Principado de Augusto tras su institucionalización en las sesiones del Senado de enero del 27 a.C. Desde las iniciales propuesta de Th. Mommsen y E. Kornemann hasta la actualidad se observa un debate ciertamente agotador, en el que todas las hipótesis posibles han sido exploradas; la explicación de este panorama puede encontrarse tanto en la ambivalencia de los datos disponibles como en la severa limitación de los indicios que nos proporcionan.

Los elementos fundamentales de la argumentación esgrimida a favor de las diversas hipótesis han estado constituidos por las referencias de la tradición literaria o epigráfica, la titulación de las colonias, las tribus a las que se adscriben sus ciudadanos y, finalmente, la procedencia de los colonos con los que se realizó la deductio. La tradición literaria y la documentación epigráfica pueden considerarse como concluyentes en relación con la fundación de dos colonias; se trata de las deductiones de la colonia Romula Hispal y Genetiva Urso. La primera, la colonia Romula Hispal, es mencionada como tal por Plinio, (nat. III 11) y considerada por Isidoro de Sevilla (Etym. XV 1.71) como fundación de César; la historiografía es unánime al valorar positivamente esta información; ${ }^{14}$ la única cuestión debatida ha sido generada por un confuso pasaje de Estrabón (III 2.1), mediante el que se ha propuesto sustentar la existencia de una

12 Gonzales Román-Mangas (1991), 227; CIL II²/7, 31. Cf. Galsterer 1971, 13; Wiegels 1982, 40-11; GonZÁlez RomÁn 1991, 89.

13 NiCOLET 1988, 182-199.

14 RE VIII, 2, cols. 1963-1965; VitTinghoff 1951, 74; GARCía y Bellido 1959, 462-463; SALMON 1969, 164; Galsterer 1971, 19; Brunt 1971, 590; Blanco 1984², 119; Marín Díaz 1988, 207-209; GonzÁlez 2005, 295; ORDÓÑEZ 2011, 54. 
segunda colonia denominada Baitis, para la que se propuso incluso su localización en Triana. Considero acertada la solución propuesta por S. Ordoñez, ${ }^{15}$ quien subraya la inexistencia de restos arqueológicos romanos en Triana y propone que el término Baitis sea considerado en el texto como mera especificación geográfica de colonia; los veteranos asentados recientemente (neosti), presentes en el mismo texto, deben interpretarse como nuevos soldados licenciados integrados en la colonia por Augusto; es posible que L. Blattius L. F. Ser. Ventinus, ${ }^{16}$ tribuno militar de las legiones $V$ Alauda y X Gemina, formara parte de los mismos; los coloni y los incolae hispalenses le honraron en el correspondiente epígrafe de fines del s. I a.C. o inicios del I d.C., en el que se hace constar que ejerció la edilidad y duovirato en la Colonia Romula.

La información sobre Genetiva Urso es definitivamente concluyente en relación con el proyecto de su deductio, la aprobación de la ley fundacional y su puesta en práctica; como es bien conocido, los tres actos correspondieron respectivamente a C. Cesar, M. Antonio y Asinio Polión; ${ }^{17}$ en consecuencia, su fundación se proyectó desde el 45 a.C. al 43 a.C. y abarcó la dictadura de César y los años posteriores a su muerte previos a la batalla de Filipos. Semejante dinámica se debe tener en cuenta, ya que los programas fundacionales de colonias entre los idus de marzo del 44 a.C. y septiembre del 31 a.C. se vieron condicionados por vicisitudes políticas inherentes a las relaciones de poder y por los reiterados conflictos militares.

Para la adscripción del resto de las colonias debemos utilizar elementos menos concluyentes y con frecuencia de carácter meramente indicativo. Entre ellos se encuentran los nuevos apelativos de las colonias yuxtapuestos a sus antiguos topónimos. La conservación de éstos últimos marcaba la continuidad ocupacional topográfica tras la fundación de la colonia; no obstante, ilustraba también la memoria histórica del destino de los habitantes de los oppida destruidos o de los partidarios del vencedor en el decurso de la guerra civil. Las limitaciones de este tipo de argumentación son en cualquier caso evidentes; de hecho, en alguna colonia, como Salaria, carecemos de tales elementos; en otra, como Iliturgi, los apelativos de la nueva titulación se derivan de su denominación anterior, cuando tan sólo era un oppidum privilegiado, que fue promocionado posteriormente como municipio.

En los apelativos se puede observar una clara polarización en su contenido entre los que poseen un carácter estrictamente augural y aquellos que se integran, conforme a los nuevos patrones helenístico-romanos, en la exaltación y vinculación al poder personal. Entre los primeros, debo mencionar el de Virtus y el de Claritas, presentes respectivamente en Ituci y en Ucubi ${ }^{18}$ ambos exaltan cualidades de carácter eminentemente militar, relacionadas con el valor, la nobleza y la reputación de sus colonos. Como se puede ver en el listado, estos apelativos augurales no son excluyentes de

15 ORDOÑEZ 1998, 49-72; ORDÓÑEZ 2011, 53-57.

16 CIL II, 1176; CILA II, 1, 20.

17 RE IV, 1 cols. 527; Vittinghoff 1951, 74; García y Bellido 1959, 465; Salmon 1969, 135; Galsterer 1971, 78; Brunt 1971, 590; Galsterer-Kröll 1975, 122; Marín Díaz 1988, 211-213; CraWford 1996, I, 393-454; González Román 1997, 153-170; GonZÁlez 2005, 295-296; Caballos 2005, 413-428; Caballos 2006, 336-338 y 345-346; PACHÓN 2011, 189.

18 Caballos 1979, 273-281; Marín Díaz 1988, 209 y 211; Lacort Navarro 1992, 195-209; GonzÁlez 2005, 295-296; SAQUETE 2011, 167-182. 
otros en las titulaciones de las colonias de la Bética; en realidad, se yuxtaponen a los que expresan el vínculo con el deductor mediante la incorporación de algún elemento de carácter onomástico.

En cualquier caso, son precisamente éstos últimos los que nos ofrecen elementos indicativos de carácter contextual, aunque cronológicamente imprecisos. En una mera aproximación a su significado me permito realizar algunas consideraciones, que pueden en principio sugerir determinadas valoraciones históricas. Concretamente, se observa, ante todo, la presencia de apelativos claramente vinculados con los antepasados míticos o reales de la familia Iulia; tal es el caso de Hasta Regia, Romula Hispal y Genetiva Urso. En los dos últimos casos, la vinculación con los progenitores míticos de la familia Iulia es evidente, ${ }^{19}$ pues remitían al fundador de Roma y a Venus Genetrix; en el primero, lejos de hipótesis vinculadas a la tradición local, el apelativo se vinculaba también a la misma familia en tanto que se derivaba, como ya anotó B. Galsterer Kröll, ${ }^{20}$ con la abuela de César, perteneciente a la familia de los Marcii Reges. Es cierto que la tendencia a la exaltación heroica de sus antepasados por la nobilitas formaba parte de las tradiciones convencionales de las familias aristocráticas romanas y se integraban como un elemento que condicionaba el cursus honorum. No obstante, el desarrollo de la guerra civil redimensionó su uso y significado.

La presencia del apelativo Iulia es mayoritaria en el conjunto de los títulos coloniales de la Hispania meridional; se encuentra presente en Acci, Ituci, Traducta Tingentera y Ucubi; la ausencia en estos casos de otros apelativos yuxtapuestos excluye cualquier duda sobre la relación directa entre su formulación y el acto fundacional de las colonias respectivas. La situación es diferente en el caso de la Colonia Iliturgita$n a$, debido a que la presencia en su titulación del apelativo Forum Iulium proyectó la continuidad de la denominación del municipio precedente; de hecho, en el inventario de Plinio (nat. III 10) se recoge ya con este título, aunque sin el estatuto colonial.

La relevancia del apelativo Iulius en las titulaciones coloniales de la Hispania meridional no posee un carácter excepcional en relación con el resto del Imperio; semejante consideración nos permite pensar que obedeció a condicionantes generales más que a peculiaridades del propio territorio. No considero arriesgado por ello proponer que semejante proyección se acentuó a medida que la guerra civil se desarrolló entre cesarianos y cesaricidas con los conflictos fundamentales de Filipos en el 42 a.C. y Nauloco en el 36 a.C., y posteriormente en el acto final de la guerra civil en Accio, que concluyeron con las conocidas victorias de los cesarianos y de Octaviano. En este sentido, se puede suponer que la extensión de este apelativo corría paralela a las victorias de la familia Iulia en el decurso de la guerra civil. Semejante reflexión debe considerarse como una mera hipótesis, que requiere una fundamentación inexistente en el panorama actual. Por ello retomo la explicación general que L. Keppie ha propuesto para la difusión del apelativo Iulius ${ }^{21}$ su presencia pudo remitir tanto a la planificación cesariana como a denominaciones realizadas en su honor, que pudieron corresponder a un momento inmediatamente posterior a las victorias de Filipos, Nau-

19 GonZÁlez - Stylow 1998, CIL II²/7, 287; OrdóÑEz 1998, $72-77$.

20 Galsterer - Kröll 1972, 125; Marín Díaz 1988, 207; GonZÁLeZ 2011, 224.

21 KeppIe 1983, 14-22. 
loco y Accio; el momento posterior al acto final de la guerra civil debió de poseer una relevancia especial a tenor de la mencionada información de las Res Gestae.

En cambio, ninguna duda cabe plantearse sobre la vinculación fundacional a Augusto de las dos colonias de la Hispania meridional, que ostentaban exclusivamente su nombre en la titulación; se trata de Augusta Gemella Tucci y de Augusta Firma Astigi. El único problema que se plantea en relación con su deductio radica en la fijación del momento preciso en el que se produjo; a falta de elementos concluyentes, podemos pensar que se fundaron o bien en los años de su primer viaje a Hispania tras la fundación del Principado, es decir, en los años 27-24 a.C. con el referente de Emerita Augusta; o bien durante su segundo viaje en los años 16-13 a.C., que se fundamenta esencialmente en las mencionadas palabras de Dión Casio sobre la colonización efectuada en ciudades de la Galia y de Iberia durante estos años.

Un posible desarrollo de esta problemática puede obtenerse a partir de la valoración de los datos relativos a las colonias mencionadas en aspectos tales como la tribu en la que se inscribieron sus ciudadanos y la vinculación de los colonos a determinadas unidades legionarias. En ambos aspectos, la documentación debe valorarse como provisional. De hecho, se aprecia en la misma la ausencia de cualquier referencia a las tribus de los colonos de Asido y Traducta Tingentera. Una situación igualmente deficiente se observa en la información existente sobre la procedencia de los colonos que se integraron en las deductiones. Es cierto que la ausencia de datos en este último aspecto refleja las peculiaridades de dos colonias, en las que la información disponible apunta hacia una transformación de la realidad municipal preexistente; tal ocurrió en los casos de Asido y de Iliturgi. No obstante, su ausencia en Hasta Regia, en Ituci y en Ucubi se debe a las limitaciones actuales de la información disponible.

Los estudios realizados en las últimas décadas sobre las tribus de Hispania en general y de la Bética en particular han permitido concluir con la vinculación respectivamente de dos de las tribus mayoritariamente documentadas, la Sergia y la Galeria, a César y a Augusto. ${ }^{22}$ No obstante, la reflexión sobre las tribus en las colonias de la Hispania meridional me permite realizar algunas consideraciones dentro de este marco general y partiendo de esta premisa generalmente aceptada. Una primera consideración está constituida por la valoración de la proyección de las tribus en las colonias; concretamente, las que se encuentran más documentadas y tuvieron una mayor implantación en las colonias de la Hispania meridional fueron efectivamente la Sergia y la Galeria; semejante hecho avala indudablemente la importancia de la actividad desarrollada por César y su hijo adoptivo en el ámbito de los proyectos o de las fundaciones coloniales.

No obstante, una mayor pormenorización permite observar en el actual estado de la documentación la existencia de colonias en las que se constata solo una tribu. Se trata concretamente de la tribu Sergia en los casos de Hasta Regia ${ }^{23}$ y de Salaria,$^{24}$ y

\footnotetext{
22 KubitscheK 1889, 169-183; Ross TAYlor 1966; Wiegels 1985, 11-71; CASTILlo 1988, 233-243; GonZÁLEZ 1989, 133-153; GonZÁLEZ 1996, 65-91; GONZÁLEZ 1998, 33-49; FORNi 1996-2007.

23 Se constata en CIL II 5405 y 1306. Cf. Wiegels 1985, 35; PADILla 1989, 185-192; GonzÁlez 2001, 231-232; Díaz Ariño 2008, 199-200; Martín Arroyo SÁnchez 2013, 176-178.

24 CIL II 3329; CILA III, 542 y p. 401; WIEGELS 1985, 133.
} 
de la tribu Galeria en Iliturgi, ${ }^{25}{ }^{2 t u c i}{ }^{26}$ y posiblemente en $U c u b i,{ }^{27}$ y, finalmente de la tribu Papiria en Astigi. ${ }^{28}$ En relación con la adscripción exclusiva de la Sergia considero oportuno recordar que el apelativo de Asta Regia remitía a la familia cesariana de los Marcii Reges, y que desconocemos la titulación de Salaria. En las colonias con adscripción única a la tribu Galeria se aprecia que las tres llevan el apelativo Iulius; no obstante, su valoración debe tener en cuenta que la titulación de Iliturgi procedía de su denominación municipal como Forum Iulium, mientras que en los casos de Ituci y Ucubi se yuxtapone a otros elementos augurales, que formaban parte de los valores inherentes a los milites de las legiones romanas.

La documentación existente sobre las tribus presentes en Astigi puede valorarse desde el punto de vista cuantitativo como excepcional; ${ }^{29}$ en la misma están presentes, asimismo, las tribus Galeria y Palatina en individuos que no poseían una origo astigitana, sino que proceden de la Galia y de Clunia; en consecuencia, sus ciudadanos estuvieron inscritos sólo en la Papiria, que constituyó también la tribu de Emerita Augusta. La excepcionalidad de la presencia de esta tribu en las ciudades hispanas tiene paralelos en el resto del Imperio, donde se documenta exclusivamente en la Galia Narbonense y en Macedonia; su explicación no ha encontrado repuestas satisfactorias en el panorama historiográfico.

El fenómeno mayoritario está constituido por la presencia de las tribus Sergia y Galeria en la misma colonia; tal es el caso de Corduba, ${ }^{30}$ Hispalis $^{31}{ }^{31}$ Tucci ${ }^{32}$ y Urso. ${ }^{33}$ La búsqueda de una explicación a esta duplicidad se ve limitada por los distintos contextos cronológicos en los que se enmarcan las deductiones de las colonias respectivas; éstos oscilan desde al menos la dictadura de César a la fundación del Principado; las explicaciones propuestas han defendido hipótesis específicas para cada caso; en el de la Colonia Patricia Corduba se mantiene la hipótesis de que su presencia, documentada de forma especialmente reiterada, remitiría a la fundación de la colonia latina por Claudio Marcelo a mediados del s. II a.C. ${ }^{34}$

Sugiero la consideración de otras dos hipótesis. La primera está constituida por la posibilidad de que se produjeran en ellas nuevos asentamientos de colonos tras la deductio originaria; el fenómeno no es ajeno al contexto del periodo triunviral y del Principado de Augusto; Veleyo Patérculo (II 81) lo registró en el pasaje mencionado; los datos relativos a la colonización de la península italiana son asimismo concluyentes; las titulaciones de las colonias lo recogen en sus propias formalizaciones,

25 CILA III, 233; CIL II ${ }^{2} / 7,36$; WIEGELS 1982, 203-204.

26 CIL II ${ }^{2} / 5$, 409. Cf. KuBITSCHEK 1889, 176; WIEGELs 1985, 45-46.

27 CIL III, 7060; CIL II²/5, 118; Cf. KubitscheK 1889, 182; Wiegels 1985, 60; Saquete 2011, 170.

28 KubitscheK 1889, 170-171; Wiegels 1985, 17-18; OrdóÑEZ 1988, 49 -50; GoNZÁlez 1995, 283-284; CIL II $\mathrm{II}^{2} / 5,339$.

29 Cf. ORDóÑEz 1988, 49 y 191.

30 Cf. KubitscheK 1889, 173; Wiegels 1985, 30-33; Rodríguez Neila 1988, 216; Knapp 1983,12 y 28-29; CIL II ${ }^{2} / 7,81$; VAQUERIZO 2011, 19.

31 Cf. KubitscheK 1889, 174-175; Le Roux 1982, 73-74; Wiegels 1985, 36-38; OrdóÑEZ 1998, 57-58; ORDÓÑEZ 2011, 55-56.

32 Wiegels 1985, 59-60; Serrano Delgado 1987, 45; González Román 2011, 144-145.

33 Cf. KubitscheK 1889, 182-1833; Wiegels 1985, 64-65; GonZÁLez 1989, 133-153 CIL II²/5, 287.

34 KNAPP 1980, 61-71; StYlow 1995, 61. 
especialmente a través de la yuxtaposición de los apelativos Iulia y Augusta; la mencionada alusión de las Res Gestae a la compra de tierras por el príncipe con destino a nuevos colonos durante diversos consulados, posteriores a la deductio, constituye asimismo un argumento a tener en cuenta; finalmente, un controvertido pasaje de Estrabón (III 2.1), referido a Hispalis, puede ser interpretado en la misma dirección; en él se subraya el carácter comercial y la importancia del emporion de esta ciudad; pero ello no era óbice para que el geógrafo anote que el aumento de su prestigio se debió a que el emperador, es decir, Augusto, había asentado recientemente nuevos colonos.

Una segunda reflexión me hace pensar en la continuidad de la movilización de los legionarios cesarianos y de sus unidades militares tras el asesinato del dictador. El fenómeno no era ajeno a las reformas que Dión Casio (XLIII 39.5) reseñó sobre su actividad tras su victoria en Munda, de la que destacó la concesión de la ciudadanía romana, el título de colonos y la inmunitas. En cualquier caso, la presencia de individuos adscritos a la tribu Sergia no implicó ineludiblemente la constitución de una comunidad cívica de rango colonial o municipal; de hecho, J. W. Kubitschek ${ }^{35}$ ya anotó la hipótesis de que peregrinos promocionados por César e inscritos en la tribu Sergia fueran incluidos en los censos coloniales de las deductiones de Octaviano y de Augusto. En cualquier caso, una mayor precisión sobre esta cuestión puede obtenerse del análisis, que realizaremos ulteriormente, de las distintas unidades militares a las que pudieron pertenecer los colonos asentados.

La interpretación sobre el significado de las tribus documentadas en las colonias de la Hispania meridional debe atender asimismo al significado de aquellas cuya presencia es excepcional en el panorama hispano; me refiero concretamente a la tribu Pupinia documentada en $A c c i,{ }^{36}$ a la Papiria de Astigi ${ }^{37}$ y a la Voltinia de Tucci. ${ }^{38}$ La tribu Pupinia se encuentra documentada junto a la Galeria en dos inscripciones de Acci de los siglos II y III, correspondientes a C. Valerius Restitutus y a M. Iunius Hispanus; se trata de una tribu completamente excepcional tanto en Hispania como en el resto del Imperio, donde se documenta sólo en la Galia Narbonense, en la Civitas Urbs Baeterrensis (Beziers); los restantes testimonios proceden de la Regio VI y X de Italia.

La colonia astigitana se caracterizó también por la presencia de una sola tribu, la Papiria, en la que se inscribieron sus ciudadanos. Ésta, como anotamos, es asimismo excepcional en Hispania y su presencia sólo se documenta entre los colonos de Emerita Augusta, hecho que posiblemente no sea una mera coincidencia; con anterioridad a su amplio uso por Trajano, esta tribu sólo se constata puntualmente en la Galia Narbonense y en Macedonia; debemos reseñar que en la Galia fue la colonia de Narbo Martius la que inscribió sus colonos en esta tribu, y que este hecho se relacionó posiblemente con el asentamiento de nuevos veteranos de la Legio $X$ en el contexto cronológico al que nos estamos refiriendo.

35 KuBITSCHEK 1889, 151.

36 KubitscheK 1889,188; Wiegels 1985, 89; Serrano Delgado 1987, 45; GonzÁlez Román 2011, 308-309.

37 Cf. nota 28.

38 KubitscheK 1889,181-182; Wiegels 1985, 59-60; GonZÁlez Román 2011, 144. 
Finalmente la tercera tribu de carácter excepcional corresponde a Tucci, donde las documentadas están constituidas por la Sergia, la Galeria y la Voltinia; las dos primeras reiteran con su presencia el carácter mayoritario de la adscripción de los colonos a estas tribus en la Hispania meridional; en cambio, la tribu Voltinia se encuentra documentada excepcionalmente en la onomástica tuccitana en el caso de Sex. Valerius Sex.f. Clemens; la cronología de la correspondiente inscripción nos permite sustentar que se trató de uno de los colonos fundadores; su presencia es excepcional en Hispania, pero, en cambio, fue también la tribu específica de la Galia Narbonense.

El panorama existente de las tribus coloniales limita su valoración e interpretación histórica. En cualquier caso, además de ratificar la importancia de la actividad específica de César y Augusto en la conformación de los ciudadanos integrados en el censo de las colonias, nos constata la existencia de otra dualidad en relación con la procedencia de los colonos; me refiero, específicamente, al hecho de que las tribus excepcionalmente documentadas, como la Pupinia, Papiria y Voltinia, se encuentran documentadas en Italia y en la Galia Narbonense, de donde pudieron proceder los ciudadanos inscritos en ellas. Semejante contexto pudo condicionar la proyección de particularidades en las colonias hispanas en ámbitos diversos como el de la conformación de la comunidad ciudadana y el de sus privilegios específicos.

El otro elemento, que nos permite abordar una mejor comprensión del hecho fundacional de las colonias de la Hispania meridional, está constituido por las unidades legionarias documentadas en su epigrafía y en su numismática. El número de legiones constatadas alcanza casi la decena en los datos conocidos de Acci, Astigi, Hispalis, Tucci y Urso. La identificación de las legiones ha suscitado en casos puntuales divergencias historiográficas, que se centran en torno a dos cuestiones; la más importante de ellas está constituida por la delimitación de las relaciones entre los milites documentados en cada colonia y los colonos asentados originariamente; la posibilidad de sustentarlas sobre bases sólidas se enfrenta a enormes dificultades, debido al contenido de los epígrafes y a su contexto cronológico. En cualquier caso, se aprecia un panorama ciertamente heterogéneo, en el que la proyección de colonos en las diversas deductiones pudo proceder tanto de una como de varias legiones. De no menor relevancia es el problema de la delimitación de las causas y del contexto histórico, que condicionaron la selección de los milites asentados.

La proyección de elementos de las unidades legionarias no es uniforme, ya que se aprecia una oscilación entre una y tres legiones en el conjunto de las colonias. En $A c c i$, las emisiones conmemorativas no dejan lugar a duda sobre la procedencia de los colonos de las legiones I y II; ${ }^{39}$ concretamente, las enseñas de las unidades legionarias y los estandartes de dos manípulos se reiteran en los reversos de una de las emisiones de Augusto, en otra de Tiberio y en la que se realizó durante el reinado de Calígula. Existen, en cambio, diferencias historiográficas relacionadas con la identificación de las unidades legionarias; la Legio II se puede identificar con la homónima mencionada en el curso de las guerras civiles en Hispania; se trataba de una legión reclutada en Italia, que permaneció estacionada durante bastante tiempo en Hispania

39 Vittinghoff 1952, 88; Galsterer 1971, 69; Brunt 1971, 127; Chaves 1976, 141-158; SANTERo 1972; GonZÁLEz Román 2011, 309-310. 
en el desarrollo final de la crisis republicana; con posterioridad, conformó la Legio II Augusta del Principado. ${ }^{40}$

En cambio, se ha propuesto identificar la Legio I con diversas unidades legionarias; entre ellas se encontraría la posterior Legio I Augusta del Principado; semejante hipótesis ha permitido incluso sustentar la fijación de la fundación de la colonia en los primeros años del Principado de Augusto. En clara contraposición se encuentra la teoría, defendida por J. M. Santero, que propone identificarla con la Legio Vernacula que, según el Bellum Alexandrinum (53.5), estaba formada por "nacidos en la provincia". ${ }^{41}$ Precisamente, las reiteradas referencias existentes en las fuentes a esta unidad legionaria han suscitado toda una diversidad de cuestiones; entre ellas se encuentran las relativas al nombre de la legio, que debe considerarse como propio, y la de su composición social, que puede estimarse como iuxta, es decir, formada consecuentemente por ciudadanos romanos asentados en la Provincia Hispania Ulterior.

Una situación más compleja presenta la delimitación de las unidades legionarias que participaron en la fundación de Astigi. La documentación epigráfica es nuestra única fuente de información; las inscripciones descubiertas aluden a nuevas unidades militares; al mismo tiempo la revisión del corpus epigráfico ha permitido excluir las relaciones previamente sugeridas. ${ }^{42}$ Las últimas propuestas consideran que la colonia Firma Astigi fue fundada con unidades procedentes de las legiones II Pansiana, IIII Macedonica y VI Victrix. Llama la atención en estas unidades la presencia de una legión como la II Pansiana que lleva como apelativo el nomen del cónsul del 43 a.C., C. Vibius Pansa, que falleció este mismo año durante la guerra de Módena en la batalla de Forum Gallorum; Veleyo Patérculo reseñó la participación de Octaviano como propretor en este conflicto; en consecuencia, podemos suponer que tras su muerte la legión de Pansa se integró entre las que eran partidarias del hijo adoptivo de César. El epígrafe honorífico, en el que se documenta la presencia de esta unidad en Astigi, honra a uno de los primeros augures y duoviros de la colonia, a L. Caninius Pomptinus, de origen itálico, que había sido centurión y praepositus de esta legión.

La Legio IIII Macedonica había sido originariamente cesariana; tras el asesinato del dictador hizo defección a favor de Octaviano en el mismo contexto de la guerra de Módena; en su actividad posterior a la finalización de las guerras civiles destacó su participación en las guerras cántabras a partir de un momento impreciso; se ha defendido el 26 a.C., aunque actualmente se tiende a aceptar que tan sólo intervendría en la última fase de la guerra, en la campaña dirigida en el 19 a.C. por M. Agripa; ${ }^{43}$ como es conocido, esta unidad se asentó en los castra de Herrera de Pisuerga hasta su traslado a Germania, a Maguncia, en torno al 40 d.C. La VI Victrix ${ }^{44}$ remitía también

\footnotetext{
40 Le Roux 1982, 61-62; Keppie 2000, 15-16; GonZÁlez Román 2011, 309-310.

41 SANTERo 1972, 206-216; GonZÁLeZ RomÁn 2011, 309-310.

42 OrdóÑEZ 1988, 49; GonZÁlez 1995; CIL II²/5, p. 339; SÁEZ ET ALII 2001, 344-352; GarCía Dils 2011, 104-106.

43 García y Bellido 1961, 119-120; Roldán 1974, 194; GonZÁlez Echegaray - Solana 1975, 151203; Le Roux 1982, 61-65; Gómez Pantoja 2000, 105-117; Morillo Cerdán 2000, 609-610; GarCía Dils 2011, 105-106.

44 García y Bellido 1961, 124-125; Roldán 1974, 200-201; Le Roux 1982, 61-65; Morillo Cerdán - García Marcos 2000, 591-592.
} 
su origen al bando cesariano; participó activamente en la guerra de la Galia y en el desarrollo de la guerra civil en Hispania en el 45 a.C.; una parte de sus contingentes se integró en el ejército de Octavio y posteriormente participó en las guerras contra los pueblos del norte, especialmente contra los astures.

La dualidad está asimismo presente en las legiones participantes en la fundación de Tucci, en cuya documentación epigráfica se aprecia la presencia de milites de la IIII Macedonica y X Gemina. En el caso de Legio IIII Macedonica la vinculación se reitera en dos epígrafes, procedentes uno de Tucci y otro de Mogontiacum (Maguncia). ${ }^{45}$ Nos interesa destacar especialmente el primero, procedente del foro de la colonia, en el que se honra a C. Iulius Scaena, inscrito en la tribu Sergia, que fue decurio equitum y centurio hastatus primus de dicha unidad; en la colonia ostentó el duovirato durante el Principado de Augusto y es muy posible, en consecuencia, que formara parte de los fundadores de la colonia. La presencia de la Legio X Gemina se documenta también en dos casos; ${ }^{46}$ uno de ellos corresponde al miles L. Marcius Marcianus, inscrito en la tribu Sergia. El carácter cesariano de esta unidad es aceptado usualmente, aunque tanto su origen como sus vicisitudes durante la guerra civil son ciertamente complejas y confusas; en cualquier caso, formó parte del exercitus Hispanicus, que combatió contra los pueblos del norte y permaneció en la zona, en el campamento de Petavonium (Rosino de Vidriales), hasta su traslado a Panonia en el 62-63. ${ }^{47}$

Finalmente, debemos comentar la presencia de la Legio XXX en Urso; su vinculación a esta colonia se constata en una inscripción en la que se menciona al centurión C. Vettius C. f., adscrito a la tribu Sergia, como dedicante de un epígrafe votivo al Genio de la colonia; ${ }^{48}$ hace constar en la misma que fue IIviro dos veces. Esta unidad militar fue reclutada en el 49 a.C. en Italia y participó con posterioridad en el desarrollo de las guerras civiles en Hispania, donde se constata su presencia en el 49 a.C. a las órdenes del cesariano Q. Casio Longino y en el 43 a.C. comandada por C. Asinio Polión; con posterioridad sería disuelta por Augusto. La inscripción se puede datar en época triunviral a tenor de sus caracteres paleográficos. En consecuencia todo ello permite concluir que $C$. Vettius formó parte de los fundadores de la colonia. El dato puede ser asimismo indicativo del carácter militar de la fundación; semejante valoración cuestiona la concepción tradicional, que hacía de Urso una colonia fundada con colonos procedentes de la ciudad de Roma; esta hipótesis se sustentaba fundamentalmente en el apelativo urbanorum, que Plinio le adscribe; éste no se documenta en la Lex Ursonensis y puede ser relacionado asimismo con el lugar de reclutamiento de la unidad legionaria.

Los datos precedentes permiten concluir que las fundaciones coloniales de la Hispania meridional tuvieron fundamentalmente un carácter militar; este panorama es coherente con la visión reseñada de las Res Gestae. En el conjunto de las legiones predominan las de origen cesariano, que es incuestionable en los casos de la II, IIII,

5 CIL II²/5, 82; CIL XIII, 6856; GoNZÁLEZ RoMáN 2011, 142-143.

46 AE 1929, 189; CIL II²/5, 83; Serrano Delgado 1987, 49-50; GonzÁlez Román 2011, 143.

47 García y Bellido 1961, 130; Roldán 1974, 206; Le Roux 1982, 61-65; Morillo Cerdán- García MARCOS 2000, 592-594.

48 CIL II, 1404; CILA 3, 620. Cf. Le Roux 1982, 50-51; GonZÁLEZ 2005, 295-296. 
$X$ Gemina y $X X X$; tan sólo en los dos casos restantes, la II Pansiana y la Legio I se observa una procedencia diferente. La II Pansiana se vinculó a Octaviano tras la guerra de Módena; formaría parte de ejército del triunviro al igual que la mayoría de las legiones cesarianas mencionadas anteriormente. Un origen distinto pudo tener la Legio I, debido a la posibilidad de que estuviera reclutada entre los ciudadanos romanos asentados en Hispania en el curso de la guerra civil entre César y Pompeyo. Las deductiones militares fueron mayoritarias pero no únicas; el caso de Asido nos documenta la transformación de los municipes en coloni; ${ }^{49}$ Iliturgi constituye un caso similar aunque con cronología imprecisa; dentro de este mismo contexto puede también incluirse la Colonia Traducta Tingentera, integrada según el pasaje de Estrabón ${ }^{50}$ por colonos romanos y gentes de Zilis y Tingis.

La especificidad de las fundaciones debió de condicionar el carácter de las colonias. En el caso de la Hispania meridional se constata en este sentido la presencia de dos elementos que pueden ser ilustrativos de este fenómeno; se trata de la inclusión del apelativo Gemella en su titulación y de la concesión de derechos específicos, que desarrollaban los privilegios inherentes al estatuto colonial. La presencia del apelativo Gemella se documenta en los casos de Acci y Tucci. Su explicación ha suscitado divergencias en la historiografía; en las primeras interpretaciones se relacionó con la posible presencia de dos legiones que participarían en la deductio; más recientemente se ha reformulado esta hipótesis y se ha propuesto que el apelativo pudo corresponder a una de las legiones con las que se fundó la colonia, que se conformó a partir de contingentes procedentes de dos legiones; el fenómeno se constata entre las unidades legionarias pompeyanas que combatieron en Farsalia. ${ }^{51}$ Ningún indicio permite concluir que fuera el caso de las mencionadas colonias hispanas; tampoco existen elementos que permitan derivar el apelativo Gemella de las dos legiones, ya que su uso no se aprecia en circunstancias similares.

Considero, como he expuesto en trabajos anteriores, ${ }^{52}$ que es preferible relacionar este apelativo con las implicaciones que tuvieron las deductiones en los casos en los que estas se produjeron sobre o junto a una comunidad preexistente; de hecho, las fundaciones de las colonias de Acci y Tucci se realizaron junto al preexistente oppidum bastetano o túrdulo, cuya realidad material subsistió. La tradición literaria y más específicamente Plinio alude a estas comunidades con el apelativo vetus; en la Naturalis Historia se registra la existencia de un Tucci Vetus y de un Astigi Vetus, que constituyeron los precedentes indígenas de las respectivas colonias romanas; su persistencia posterior a la deductio queda documentada en el inventario de Plinio (nat. III 12 y 10) donde Astigi Vetus es incluido como oppidum libre, mientras que Tucci Vetus lo es como estipendiario.

Un epígrafe descubierto en el Cortijo de Periate (Píñar, Granada) y dado a conocer en los últimos años arroja nuevos elementos sobre esta cuestión; procede del s. II y

49 Cf. Padilla Monge 1985, 307-327; GonZÁLEZ 2005, 297-298; GonZÁlEZ 2011, $277-281$.

50 Estrabón, III 1.8. Cf. GonZÁLEZ 2005, 298-299; GoZALBES 2011, 251.252.

51 STYLOW 2000, 775-806.

52 González Román 2002, 56-58; GonzÁlez Román 2011, 316-317. En el mismo sentido, Bendala 2001-2001, 413-432; LAFFI 2004, 235-254. 
en el mismo se honra a L. Aemilius Propinquus. ${ }^{53}$ Lo relevante de su contenido está constituido por el hecho de que es calificado como accitanus vetus, mientras que los decuriones que emiten el decreto forman parte del ordo accitanorum veterum. Las reflexiones suscitadas subrayan la posibilidad de que nos encontremos ante un nuevo municipio; se ha propuesto, incluso, su posible identificación con Agatucci, una de las mansiones existentes en el recorrido de la Via Augusta por el actual territorio de la provincia de Granada.

Semejante hipótesis se enfrenta a diversas objeciones; la más relevante está constituida por el hecho de que no se haga mención a la realidad municipal en el epígrafe. Por ello y a falta de una mayor documentación, me he permitido sugerir como explicación el fenómeno de la contributio; su práctica se encuentra documentada en el capítulo 103 de la Lex Ursonensis, relativa a los movilizables por los magistrados con ocasión de la declaración del tumultum; el texto ha suscitado divergencias en su fijación y comentarios; reseño, siguiendo a U. Laffi, ${ }^{54}$ que la interpretación más plausible es la de considerar que una comunidad previamente existente haya sido considerada contributa y, en consecuencia, fusionada administrativa y jurisdiccionalmente con la colonia.

Si se acepta esta hipótesis, podemos pensar que el apelativo Gemella sería indicativo de la existencia de un proceso de integración de élites indígenas promocionadas e integradas en las fundaciones coloniales; el fenómeno puede rastrearse en los estudios de las onomásticas coloniales; en las mismas se aprecia la existencia de gentilicios excepcionales de procedencia itálica junto a una onomástica generalizada de carácter latino vinculada a las principales familias de la nobilitas; entre ellas se encuentran los Octavii en Acci y los Iulii en Tucci; ${ }^{55}$ se trataría, obviamente, de las aristocracias indígenas, favorecidas por la concesión de la ciudadanía romana en el curso de las guerras civiles. En consecuencia, se pudieron integrar tanto itálicos como hispanos en los censos coloniales de determinadas fundaciones.

Es ampliamente conocido que en la definición de las colonias romanas utilizamos dos referencias de la tradición clásica procedentes de Cicerón y de Aulo Gelio; Cicerón (De leg. Agrar. II 27-73), en el 63 a.C., las definía como propugnacula imperii; en el s. II, en cambio, Aulo Gelio (N.A. XVI 13.4) subrayaba su carácter de effigies parvae simulacraque. Es incuestionable que las fundaciones de las colonias en la Hispania meridional desempeñaron la función de control y de baluarte reseñada por Cicerón en su visión de los objetivos coloniales; éstos se contraponían de forma radical a la óptica de los populares, que preferían espacios propicios para llevar a cabo la reforma agraria. El fenómeno puede apreciarse en su proyección territorial, en la que se observan fundaciones de múltiples colonias a lo largo de la Vía Augusta; su carácter de propugnacula se materializaba en el control de los pueblos estipendiarios ubicados en la periferia del ager colonial y a través de la explotación de recursos específicos y variados de su pertica, entre los que debemos mencionar las enormes

53 Cf. Pastor 2000, 155-164; Stylow 2000, 775-806; CILA IV, 107.

54 Laffi 1966, 128 ss; Rodríguez Neila 1977, 55-61; González Román 2002, 94-95.

55 GonZÁlez Román 2011, 145-148,152-154 y 313-314. 
posibilidades agrarias de su territorio y sus recursos mineros, presentes en los alrededores y en el propio ager en los casos de Acci y Salaria.

La identificación, en cambio, de las colonias con las parvae effigies simulacraque Populi Romani poseía ciertas especificidades en el contexto de la organización provincial de fines de la republica y del Principado de Augusto. Creo que en este contexto debemos recordar que la subordinación del territorio provincial a Roma, identificada con Italia tras la guerra social y las reformas del 49 a.C., se materializaba en diversos ámbitos, que expresaba su carácter de praedium; entre ellos se encontraban los relativos al ámbito impositivo con la presencia de impuestos que gravaban al territorio (tributum soli) y a las personas (tributum capitis); la ausencia de autonomía de sus pueblos y ciudades, sometidas al control de los gobernadores provinciales; $y$, finalmente, limitaciones en el ámbito de la propiedad, reducida a la posessio en contraposición al dominium ejercido por el Senatus Populusque Romanus sobre el ager provincialis.

Semejante contexto condicionó las consecuencias integradoras y equiparadoras de las deductiones en la Hispania meridional. Su proyección puede observarse en la información de Plinio sobre el carácter de las colonias mencionadas, en las que aprecia diferenciaciones concretas; el elemento vertebrador estuvo constituido por la posesión de privilegios específicos, que equiparaban total o parcialmente su estatuto con el de las colonias fundadas en suelo itálico. Concretamente, la Naturalis Historia especifica que la colonia accitana poseía el Ius Italicum, mientras que las colonias de Ituci, Tucci, Ucubi y Urso eran inmunes; $;{ }^{56}$ posiblemente la immunitas también sea extensible a Astigi, por el contexto del texto de Plinio; en cualquier caso, su proyección se encuentra confirmada epigráficamente en la colonia tuccitana en una inscripción del s. II (CIL II $2 / 5,69)$, en la que el flamen de las colonias inmunes de la provincia de la Bética, L. Lucretius Fulvianus, conjuntamente con su hija Lucretia Fulviana, realizaron determinadas donaciones a la Pietas Augusta.

Las concesiones del derecho itálico a Acci constituyeron un hecho excepcional, que permitió a sus colonos su equiparación con los de Italia en aspectos fundamentales relativos a la autonomía de la colonia, al dominium de sus bienes y a la immunitas. En cambio, la exención de impuestos a las colonias mencionadas les liberó del símbolo de la dependencia inherente a las provincias, que se materializaba en el pago de impuestos directo, como el tributum soli y en el tributum capitis, que los ciudadanos romanos habían dejado de pagar desde el 167 a.C. en clara relación con la eclosión del sistema provincial.

En suma, durante el segundo triunvirato, la potestas excepcional de Octaviano posterior a Accio, y el Principado de Augusto se transformó sustancialmente la situación de la Hispania meridional tanto en su vertebración interna como en sus relaciones con el centro del Imperio. Uno de los elementos catalizadores estuvo constituido por las deductiones de colonias, que jalonaron en cierta medida el proceso histórico de este periodo. Su trascendencia puede observarse en la relevancia del número de colonias fundadas. Sin embargo, su valoración no sería completa si dejáramos de

56 Nat., III 3.25 y III 3.12; GonZÁLEZ RomÁn 1991, 92-98; GonZÁLEZ Román 2002, 11-133. 
tener en cuenta que la emigración itálica, inherente al fenómeno colonial, tuvo como correlato la integración puntual de las elites indígenas; y que la situación dependiente del territorio provincial se transformó a través de las deductiones, que posibilitaron la equiparación parcial de sus territorios y de sus cives con el centro del Imperio.

\section{Bibliografía}

Alvar EzQuerra, A. (1980-1981): "Las Res Gestae divi Augusti”, Cuadernos de Prehistoria y Arqueologia 7-8, 109-140.

Bendala, M. (2000-2001): "Estructura urbana y modelos urbanísticos en la Hispania antigua: continuidad y renovación con la conquista romana", Zephyrus 53-54, 413-432.

Blanco, A. (1984²): Historia de Sevilla. La ciudad antigua (de la Prehistoria a los visigodos), Sevilla

BRUNT, P. A.

(1962): "The Army and the Land in the Roman Revolution", JRS 52, 69-86.

(1971): Italian Mampower (225 B.C.-A.D. 14), Oxford.

Brunt P. A. - Moore, J. M. (1967): Res Gestae Divi Augusti, Oxford.

Caballos, A.

(1978): “Colonia Claritas Iulia Ucubi”, Habis 9, 273-291.

(2005): "La actividad colonizadora en la Provincia Hispania Ulterior a fines de la República: la nueva tabla inédita de la ley de Osuna y el deductor coloniae", [en] E. Melchor, - J. Mellado, - J. F. Rodríguez Neika, (eds.), Julio César y Corduba: tiempo y espacio en la campaña de Munda (49-45 a. C.), Córdoba, 413-428.

(2006), El nuevo bonce de Osuna y la política colonizadora romana, Sevilla.

Castillo, C. (1988): "La tribu Galeria en Hispania: ciudades y ciudadanos", [en] Estudios sobre la Tabula Siarensis, Madrid, 233-243.

Cooley, A. E. (2009): Res Gestae Divi Augusti. Text, Translation and Commentary, Cambridge.

Craco Ruggini, L. (1987): “La citta romana dell'eta imperiale”, [en] P. Rossi, Modelli di Città. Strutture e funzioni politiche, 127-152.

Crawford, M. (1996): Roman Statutes, London.

Chaves, F. (1976): “Las monedas de Acci”, Numisma 138-143, 141-158.

Chaves, F. (ed.) (2002): Urso. A la búsqueda de su pasado, Osuna.

Degrassi, A. (1952): I Fasti consolari dell'Impero Romano dal 30 avanti Cristo al 613 dopo Cristo, Roma.

Diaz Ariño, B. (2008): Epigrafía latina republicana de Hispania, Barcelona.

EhrenberG, V. - Jones, A. H. M. (1955²): Documents Ilustrating the Reigns of Augustus and Tiberius, Oxford.

FORNI, G. (1996-2007): Le tribù romane, Roma.

GABBA, E. (1973): Esercito e società nella Tarda Repubblica romana, Firenze.

GALSTERER, H. (1971): Untersuchungen zum römischen Städtewesen auf der iberischen Halbinsel, Berlín. 
GAlsterer-KröLl, B. (1975): “Zu den spanischen Städtelisten des Plinius”, AEARq. 48, 120128.

GARCÍA y BELlido, A.

(1961): "El Exercitus Hispanicus desde Augusto a Vespasiano", AEArq. 34, 114-160.

(1959): "Las colonias romanas de Hispania", AHDE. 29, 447-512.

Gómez Pantoja, J. (2000) : “Legio III Macedonica”, [en] Y. Le Bohec (ed.), Les légions de Rome sous le Haut-Empire, Lyon, 105-117.

González Echegaray, J. - Solana Sainz, J. M. (1975), “La Legio IV Macedonica en España", $H A .5,151-203$.

GONZÁlEZ, J.

(1989): “Urso, ¿tribu Sergia o Galeria?”, [en] J. González (ed.), Estudios sobre Urso Colonia Iulia Genetiva, Sevilla, 133-153.

(1995): "De nuevo en torno a la fundación de la colonia Astigi Augusta Firma", Habis 26, 281-293.

(1996): "Las fundaciones de Augusto y la tribu Galeria", Anuari de Filologia XIX secciò D, número 7, 65-91.

(1998): "Las fundaciones de Augusto en la Bética y la tribu Galeria", [en] J. Mangas (ed.), Italia e Hispania en la crisis de la República romana. Actas del III Congreso HispanoItaliano, Madrid, 33-49.

(2005): "Colonización y latinización de la Provincia Baetica", [en] M. G. Angeli Bertinelli - A. Donati (cur.), Serta antiqua et mediaevalia. VII. Il cittadino, lo straniero, il barbaro, fra integrazione ed emarginazione nell'antichita: atti del I Incontro Internazionale di Storia Antica (Genova 22-24 maggio 2003), Roma, 283-303.

(2011), “Colonia Hasta quae regia dicitur”, [en] J. González, - J. C. Saquete (eds.), Colonias de César y Augusto en la Andalucía romana, Roma, 223-247.

GonzÁlez Román, C.

(1991): "Las colonias romanas de la Hispania meridional en sus aspectos sociojurídicos", [en] C. González Román (ed.), La Bética en su problemática histórica, Granada.

(1997): "Las deductiones de colonias y la Lex Ursonensis", Studia Historica 15, 153-170. (2002): Ciudad y privilegio en Andalucía en época romana, Granada.

(2011): “Colonia Augusta Gemella Tucci (Martos, Jaén)”, [en] J. González, - J. C. Saquete (eds.), Colonias de César y Augusto en la Andalucía romana, Roma, 129-163.

(2011): “Colonia Iulia Gemella Acci (Guadix, Granada), [en] J. González, - J. C. Saquete (eds.), Colonias de César y Augusto en la Andalucía romana, Roma, 297-341.

González Román, C. - Mangas, J. (1991): Corpus de inscripciones latinas de Andalucía. III. Jaén, Sevilla.

Gozalves, E. (2011): “Iulia Traducta y las colonias de Augusto en el norte de Marruecos", [en] J. González, - J. C. Saquete (eds.), Colonias de César y Augusto en la Andalucía romana, Roma, 249-272.

Grant, M. (1946): From Imperium to Auctoritas, Cambridge.

JACQUES, F. - SCHEID, J. (1990): Rome et l'integration de l'Empire (44 av. J. C.-260 ap. J. C.). I. Les structures de l'Empire Romain, Paris.

KNAPP, R. C.

(1980), "La epigrafía y la historia de Córdoba", Anuario de Filología 6, 61-71.

(1983), Roman Córdoba, Berkeley. 
KEPPIE, L.

(1983): Colonisation and Veteran Settlement in Italy 47-41 b. C., Roma.

(2000): “Legiones II Augusta, VI Victrix, IX Hispana, XX Valeria Victrix", [en] Y. Le Bohec (ed.), Les légions de Rome sous le Haut-Empire, Lyon, 25-37.

Kornemann, E.: “Colonia”, [en] RE IV, col. 510-588.

KubItSCHEK, J. W. (1889) Imperium Romanorum tributim descriptum, Roma, reimp. 1972.

Lacort Navarro, P. J. (1992): “Colonia Claritas Iulia Ucubi, actual Espejo (Córdoba)”, Dialoghi di Archeologia 10, 195-209.

LAFFI, U.

(1966): Adtributio e contributio. Problemi del sistema politico administrativo dello statoromano, Pisa.

(2003): "La colonizzazione romana nell'età della repubblica", Atti dei Convegni Lincei. Il fenomeno coloniale dall' Antichità ad oggi, Roma, 37-52.

(2004): "Le colonie romane con 1' appelativo Gemela o Gemina", [en] Artissimum memoriae vinculum. Scritti di geografia storica e di antichità in ricordo di Gioia Conta, Firenze, 235-254.

Lassère, J. M. (1977): Ubique populus. Peuplement et mouvements de population dans l'Afrique romaine de la chute de Carthage à la fin de la dynastie des Séveres (146 a.C- 235 p. C.), Paris.

Le Roux, P. (1982): L'armée romaine et l'organisation des provinces ibériques d'Auguste à l'invasion de 409, Paris.

Mann, J. C. - Rosan, M. M. (1983): Legionary Recruitment and Veteran Settlment during the Principate, London.

Martín Arroyo SÁnchez, D. J. (2013): Proyección territorial y colonización romana. El caso de Hasta Regia, Cádiz (tesis doctoral).

Millar, F.

(1977): The Emperor in the Roman World, London.

(1984): "State and Subject: The Impact of Monarchy", [en] F. Millar - E. Segal (eds.), Caesar Augustus. Seven Aspects, Oxford, 37-60.

Nicolet, C. (1988): L'Inventaire du Monde, Paris.

Mommsen Th. (1883): Die italischen Bürgercolonien von Sulla bis Vespasian, Hermes 18, 161-213.

Morillo Cerdán, A. (2000): "La legio IIII Macedonica en la Península Ibérica. El campamento de Herrera de Pisuerga (Palencia)", [en] Y. Le Bohec (ed.), Les légions de Rome sous le Haut-Empire, Lyon, 609-624.

Morillo Cerdán, A. - García Marco, V. (2000): "Nuevos testimonios acerca de las legiones VI Victrix y X Gemina en la región septentrional de la Península Ibérica”, [en] Y. Le Bohec (ed.), Les légions de Rome sous le Haut-Empire, Lyon, 589-607.

ORDÓÑEZ, S.

(1988): Colonia Augusta Firma Astigi, Sevilla.

(1998): Primeros pasos de la Sevilla romana (Siglos I a.C.-I d.C.), Sevilla.

OrdóÑez, S. - GonzÁlez AcuÑA, D. (2011): “Colonia Romula Hispalis. Líneas esenciales de su dinámica”, [en] J. González - J. C. Saquete (eds.), Colonias de César y Augusto en la Andalucía romana, Roma, 47-97. 
Pachon Romero, J. A. (2011): "De la Urso tardo republicana a la Colonia Genetiva Iulia. Un análisis desde la historiografía y la arqueología”, [en] J. González - J. C. Saquete (eds.), Colonias de César y Augusto en la Andalucía romana, Roma, 187-222.

Padilla Monge, A.

(1989): “El epígrafe CIL. II 1305”, Habis 20, 185-192.

(1985): “Asido Caesarina: constataciones acerca de su status”, Habis 16, 307-327.

PAIS, E. (1923): Storia della colonizzazione di Roma antica, Roma.

Pastor Muñoz, M. (2000); “Accitani veteres en una nueva inscripción latina de Píñar (Granada)", $H A .24,155-164$.

Rodríguez NeILA, J. F.

(1977): "Notas sobre la "contributio" en la administración municipal de la Bética romana", Archivo Hispalense 60, 185, 55-61.

(1988): Historia de Córdoba. Del amanecer prehistórico al ocaso visigodo, Córdoba.

RoldÁn, J. M. (1974): Hispania y el ejército romano, Salamanca.

SÁEZ, P. ET ALII (2001): “Cinco inscripciones romanas inéditas de Écija (Sevilla)”, Habis 32, 337-352.

Salmon, E. T. (1969): Roman Colonisation under the Republic, London.

SAntero, J. M. (1972): “Colonia Iulia Gemella Acci”, Habis 3, 203-222.

SAQuete, J. C. (2011): “Claritas Iulia y Virtus Iulia. Dos colonias romanas en el valle medio del Baetis”, [en] J. González - J. C. Saquete (eds.), Colonias de César y Augusto en la Andalucía romana, Roma, 167-182.

ScheId, J. (2007): Res Gestae Divi Augusti, Hauts faits du divin Auguste, Paris.

Segura Ramos, B. (2004): “Colonias y municipios en Tácito", Habis 35, 277-283.

Serrano Delgado, J. M. (1987): La colonia romana de Tucci, Torredonjimeno.

Syme, R. (1939): The Roman Revolution, Oxford (trad. Madrid, 1989).

StYlow, A. U.

(1995): "Corduba Colonia Patricia", [en] CIL II²/7, 61-164.

(1996): “De Corduba a Colonia Patricia. La fundación de la Corduba romana”, [en] P. León (ed.), Colonia Patricia Corduba. Una reflexión arqueológica, Córdoba, 77-85.

(1997): “Apuntes sobre las tribus romanas en Hispania”, Veleia 12, 105-123.

(2000): "Die Accitani veteres und die Kolonie Iulia Gemella Acci. Zum Problem von veteres, Alt-Stadt und Kolonie in der Hispania Ulterior", Chiron 30, 775-806.

Vaquerizo, D. - Murillo, J. F. - Garriguet, J. A. (2011): "Novedades arqueológicas en Corduba, colonia Patricia”, [en] J. González - J. C. Saquete (eds.), Colonias de César y Augusto en la Andalucía romana, Roma, 9-46.

TAYLOR, L. R. (1966): Roman Voting Assemblies from the Hannibalic War to the Dictatorship of Caesar, Michigan.

Wiegels, R. (1985): Die Tribusinschriften des römischem Hispanien, Berlín.

Vittinghoff, F. (1951): Römische Kolonisation und Bürgerrechtspolitik unter Caesar und Augustus, Mainz. 